\title{
Limiting Gastric Inflation
}

Respiratory therapists (RTs) must understand the variables that may cause gastric inflation during bag-valvemask and mouth-to-mouth ventilation. Given the clinical responsibility RTs assume in providing ventilation with a bag-valve-mask during resuscitation of cardiac arrest victims and prior to emergent tracheal intubation, they should lead the way in minimizing gastric inflation. The article in this month's issue of RESPIRATORY CARE by Dr Fitz-Clarke ${ }^{1}$ provides a predictive model that explains the factors that determine whether gastric inflation may occur. Health care professionals should be aware of the mouth pressure that will open the lower esophageal sphincter and how it may be affected during resuscitation, depending on degree of hypoxia, lung volume, diaphragmatic mechanics, abdominal pressure, and gastric distention. ${ }^{1,2}$ The combination of these physical and anatomical variables and ventilatory techniques during bag-valve-mask and mouth-to-mouth ventilation determines upper airway pressure and therefore gas distribution between the lungs and stomach. ${ }^{2-4}$ An early study on gastric inflation was conducted by Ruben et al in $1961,{ }^{3}$ who studied the minimum pressure needed to inflate the stomach in 20 anesthetized subjects prior to surgery, both before and after intubation. They reported that, with the head in the normal position, pressures $<15 \mathrm{~cm} \mathrm{H}_{2} \mathrm{O}$ rarely produced insufflation of the stomach, while pressures $\geq 25 \mathrm{~cm} \mathrm{H}_{2} \mathrm{O}$ did in most subjects. ${ }^{3}$ In an unprotected airway, distribution of ventilation volume between the lungs, esophagus, and stomach depends mainly on patient variables such as lower esophageal pressure (LESP), mouth pressure, airway resistance, and respiratory system compliance $\left(\mathrm{C}_{\mathrm{RS}}\right)$. Gastric inflation may contribute to gastric regurgitation with resultant aspiration, which was observed in $12 \%$ of subjects resuscitated for cardiac arrest where a bag-valvemask was used to provide ventilatory support. ${ }^{5}$ The objective of the predictive model presented by Dr Fitz-

Dr Barnes discloses a relationship with Mercury Medical. Mr Ward has no conflicts to disclose.

Correspondence: Thomas A Barnes EdD RRT FAARC, Northeastern University, College of Professional Studies, 360 Huntington Ave, 30 BV Boston, MA 02115. E-mail: t.barnes@ northeastern.edu.

DOI: $10.4187 /$ respcare.06239
Clarke aimed to improve the understanding of the optimal bag-valve-mask and mouth-to-mouth ventilation

\section{See the Original Study on Page 502}

technique to provide a mouth pressure and breath duration that will limit gastric inflation based on independent variables that he controlled. Should breath delivery be fast or slow, and how does inspiratory time affect the division of gas flow between the lungs, esophagus, and stomach? Dr Fitz-Clarke explained how $\mathrm{C}_{\mathrm{RS}}$ and LESP limit the tidal volume $\left(\mathrm{V}_{\mathrm{T}}\right)$ that can be delivered before gastric inflation occurs (ie, $\mathrm{V}_{\mathrm{T}}$ $>$ LESP $\times \mathrm{C}_{\mathrm{RS}}$ ) and provided an equation for summarizing the functional relationship for the volume of gastric inflation $\left(\mathrm{V}_{\mathrm{G}}\right)$ that may occur: $\mathrm{V}_{\mathrm{G}}=\mathrm{f}\left(\mathrm{V}_{\mathrm{T}}, \mathrm{T}_{\mathrm{I}}\right.$, LESP, $\left.\mathrm{C}_{\mathrm{RS}}, \mathrm{R}_{\mathrm{AW}}\right){ }^{1}$

To prevent or minimize gastric inflation, the RT must use a bag-valve-mask in a way that limits mouth pressure while providing oxygen-enriched ventilation to maintain arterial blood gases at near normal levels. The American Heart Association guidelines on cardiopulmonary resuscitation and emergency cardiovascular care recommend a bag-valve-mask technique that uses a $\mathrm{V}_{\mathrm{T}}=600 \mathrm{~mL}$ delivered 10 times/min with an inspiratory time of $1 \mathrm{s.},{ }^{6,7}$ This would result in a peak inspiratory flow of $36 \mathrm{~L} / \mathrm{min}$, which investigators have suggested may result in less gastric inflation when LESP $=20 \mathrm{~cm} \mathrm{H}_{2} \mathrm{O}$ when compared to higher flow observed with a short $0.5 \mathrm{~s}$ inspiratory time. ${ }^{8}$ These investigators reported a linear regression equation quantitating the amount of gastric inflation dependent on flow (ie, gastric inflation $=[8.668 \times$ peak inspiratory flow] - 200.60). ${ }^{8}$ Other similar bench model studies that used a LESP of approximately $20 \mathrm{~cm} \mathrm{H}_{2} \mathrm{O}$ with a flow-restricted bag-valve-mask technique with inspiratory time $>1 \mathrm{~s}$ reported less gastric inflation. ${ }^{9}{ }^{910}$ The predictive model developed by Dr Fitz-Clarke set LESP to 20, 15, 10, or $5 \mathrm{~cm} \mathrm{H}_{2} \mathrm{O}$ to account for the sphincter-tone decline measured during human hypoxic arrest. ${ }^{2}$ The predictive model shows the impact of delivering $600 \mathrm{~mL} \mathrm{~V}_{\mathrm{T}}$ in only $0.5 \mathrm{~s}$ (peak flow $=72 \mathrm{~L} / \mathrm{min}$ ) on mouth pressure and gastric inflation. Dr Fitz-Clarke also illustrated the effect of increasing inspiratory time from $1 \mathrm{~s}$ to $2.5 \mathrm{~s}$ on gastric inflation. This documented the increased duration of inspiration and lower mouth pressure along with more time for gas to pass through the lower esophageal sphincter to the stomach. 


\section{EDITORIALS}

LESP cannot be assessed during resuscitation of cardiac arrest or near-drownings. However, the longer the interval before bag-valve-mask ventilation and chest compressions, the greater the chance that the patient will become severely hypoxemic, which will thus lower the LESP from $20 \mathrm{~cm} \mathrm{H}_{2} \mathrm{O}$ to $5 \mathrm{~cm} \mathrm{H}_{2} \mathrm{O} .{ }^{2}$ Dr Fitz-Clarke's model suggests that shorter inspiratory times of $0.5 \mathrm{~s}$ should be considered when the patient is severely hypoxic to limit the time for gas to pass by the lower esophageal sphincter. It will be up to the RT and other experienced health care professionals to evaluate all factors that will affect LESP and mouth pressure, and hence the amount of gastric inflation that might occur during bag-valve-mask ventilation. This means the RT must be highly skilled in the use of the bag-valvemask and must know the $\mathrm{V}_{\mathrm{T}}$ that is being delivered and be able to control the inspiratory time. When the LESP is low and lung impedance higher than normal, the bag-valvemask technique must be modified to mitigate the potential for gastric inflation. Accordingly, experienced and new RTs alike must be aware of how gastric inflation occurs and be able to modify the way they use a bag-valve-mask to provide optimal ventilatory support. The use of 2-person bag-valve-mask ventilation, as recommended by the American Heart Association, with one rescuer holding the mask tightly to the face and the second squeezing the bag, should be discontinued. ${ }^{7}$ Mask leak is a safety feature because it may limit mouth pressure to approximately $30 \mathrm{~cm} \mathrm{H}_{2} \mathrm{O}$.

Using bag-valve-mask devices with in-line pressure gauges that show the mouth pressure generated may help RTs monitor the potential for gastric inflation and to modify $\mathrm{V}_{\mathrm{T}}$ and inspiratory time accordingly. Increasing breathing frequency to $>10$ breaths/min will shorten inspiratory time, increase mouth pressure, and may hyperventilate the patient. ${ }^{11}$ There are disposable devices that will prompt a breath every $6 \mathrm{~s}$ (10 breaths/min) and allow time for a 1-s inspiratory time, thus helping keep mouth pressure $<20 \mathrm{~cm} \mathrm{H}_{2} \mathrm{O}$. Unless the LESP is close to $5 \mathrm{~cm} \mathrm{H}_{2} \mathrm{O}$, there is no advantage to using an inspiratory time $<1$ s. $^{12}$ Unfortunately, there is no easy way to know if the LESP has dropped below $20 \mathrm{~cm} \mathrm{H}_{2} \mathrm{O}$ during a resuscitation event. Thus, health care professionals, especially RTs, must be aware of oxygenation status and assume LESP has dropped dependent on the degree of hypoxia. ${ }^{1,2}$ Studying the predictive model from $\mathrm{Dr}$ Fitz-Clarke and the accompanying figures should be required reading for all RTs attending resuscitation code calls and providing bag-valve-mask ventilation prior to emergent or elective intubations.
Thomas A Barnes EdD RRT FAARC Northeastern University College of Professional Studies Master of Science in Respiratory Care Leadership Program

Boston, Massachusetts

\author{
Jeffrey J Ward MEd RRT FAARC \\ Mayo Clinic \\ Multidisciplinary Medical Simulation Center \\ Rochester, Minnesota
}

\section{REFERENCES}

1. Fitz-Clarke JR. Fast or slow rescue ventilations: a predictive model of gastric inflation. Respir Care 2018;63(5):502-509.

2. Gabrielli A, Wenzel V, Layon AJ, von Goedecke A, Verne NG, Idris AH. Lower esophageal sphincter pressure measurement during cardiac arrest in humans: potential implications for ventilation of the unprotected airway. Anesthesiology 2005;103(4):897-899.

3. Ruben H, Knudsen EJ, Carugati G. Gastric inflation in relation to airway pressure. Acta Anaesthesiol Scand 1961;5:107-114.

4. Stallinger A, Wenzel V, Oroszy S, Mayr VD, Idris AH, Lindner KH, et al. The effects of different mouth-to-mouth ventilation tidal volumes on gas exchange during simulated rescue breathing. Anesth Analg 2001;93(5):1265-1269.

5. Stone BJ, Chantler PJ, Baskett PJ. The incidence of regurgitation during cardiopulmonary resuscitation: a comparison between the bag valve mask and laryngeal mask airway. Resuscitation 1998;38(1):3-6.

6. Kleinman ME, Brennan EE, Goldberger ZD, Swor RA, Terry M, Bobrow BJ, et al. Part 5: Adult basic life support and cardiopulmonary resuscitation quality: 2015 American Heart Association guidelines update for cardiopulmonary resuscitation and emergency cardiovascular care. Circulation 2015;132(Suppl 2):S414-S435.

7. Berg R, Hemphill R, Abella B, Aufderheide T, Cave D, Hazinski M, et al. Part 5: Adult basic life support: 2010 American Heart Association guidelines for cardiopulmonary resuscitation and emergency cardiovascular care. Circulation 2010;122(Suppl 3):S685-S705.

8. Barnes TA, Catino ME, Burns EC, Chan WK, Ghazarian G, Henneberg WR, et al. Comparison of an oxygen-powered flow-limited resuscitator to manual ventilation with an adult $1,000-\mathrm{mL}$ self-inflating bag. Respir Care 2005;50(11):1445-1450.

9. von Goedecke A, Wagner-Berger HG, Stadlbauer KH, Krismer AC, Jakubaszko J, Bratschke C, et al. Effects of decreasing peak flow rate on stomach inflation during bag-valve-mask ventilation. Resuscitation 2004;63(2):131-136.

10. De Regge M, Vogels C, Monsieurs KG, Calle PA. Retention of ventilation skills of emergency nurses after training with the SMART BAG compared to a standard bag-valve-mask. Resuscitation 2006; 68(3):379-384.

11. Aufderheide TP, Sigurdsson G, Pirrallo RG, Yannopoulos D, McKnite $\mathrm{S}$, von Briesen C, et al. Hyperventilation-induced hypotension during cardiopulmonary resuscitation. Circulation 2004;109(16):1960-1965.

12. Melker RJ, Banner MJ. Ventilation during CPR: two-rescuer standards reappraised. Ann Emerg Med 1985;14(5):397-402. 